\title{
Efficacy of Sacro-Occipital Technique on Sacroiliac Joint Instability in Females
}

\author{
EMAN M.H. SHERIF, M.Sc.*; SALWA F. ABD EL-MAGEED, Ph.D.** and \\ MAHMOUD M.I. ABD EL-GHAFFAR, M.D.***
}

The Department of Physical Therapy for Musculoskeletal Disorders \& their Surgeries, Mansoura University Hospital*, Faculty of Physical Therapy, Cairo University** and The Department of Orthopedic Surgery, Faculty of Medicine, Mansoura University***, Egypt

\begin{abstract}
Background: Sacroiliac function is considered to be important in many manual therapy systems because of the complexity and location of the Sacroiliac joint in the kinetic chain, moreover $98 \%$ of patients having low back pain had mechanical dysfunction of the sacroiliac joints.

Aim of Study: The aim of this study is to explore the effect of Sacro-occipital technique on pelvic obliquity in patients with Sacroiliac joint instability.

Patients and Methods: Thirty female patients were randomly assigned into two groups and each group consists of 15 patient. Control Group (A) treated by Therapeutic ultrasound and study Group (B) treated by Sacro-occipital technique + Pelvic belt + Therapeutic ultrasound. Referred from orthopedist with the diagnosis of Sacroiliac joint pain with mean age, weight and height 29.5 (3.8) years, 74.7 (5.3) kg, and 163 (4.4) $\mathrm{cm}$ respectively. Pelvic obliquity was objectively measured by using pelvic inclinometer.

Results: No statistically significant difference between groups in pelvic obliquity before treatment. But a significant reduction in pelvic obliquity was observed in the study group (B) compared to the control group (A).

Conclusion: The study proved that Sacro ocipital technique decreased the pelvic obliquity in patient with sacro iliac joint instability.
\end{abstract}

Key Words: Sacro-occipital technique - Pelvic obliquity Sacro iliac joint instability.

\section{Introduction}

LOW Back Pain (LBP) is a very common condition worldwide is often induced by sedentary lifestyle and lack of physical exercise [1]. The types of joint dysfunctions are classified into category I, II, and III depending on their condition [2]. Category II

Correspondence to: Dr. Eman M.H. Sherif, The Department of Physical Therapy for Musculoskeletal Disorders \& their Surgeries, Mansoura University Hospital, Egypt dysfunction is found in patients suffering from posterior Sacroiliac joint hypermobility, which can lead to buttock pain, sciatic leg pain, groin pain, hip pain, abnormal urinary frequency, and transient numbness, prickling, or tingling [3]. Furthermore, because of the position of the SI joints and the complexity of the joint movements, pelvic subluxation of these joints can lead to excessive bi-lateral pelvic tilting and the unbalanced posture [4]

Low back pain during the course of pregnancy is a common experience for many women. There are three prevalent groups of theories regarding the etiology of this occurrence: (1) Hormonal, (2) Vascular or (3) Mechanical. The hormonal and vascular theories insinuate that the back symptoms are a normal and expected occurrence, which will spontaneously resolve after completion of term. The mechanical approach investigates the cause was secondary to strain on the connective tissues in the lumbo-sacral region and also suggests the possibility that the condition existed prior to becoming pregnant, as well as a potential for chronicity and/or recurrence after delivery [ $\boldsymbol{\Omega}$.

As the name Sacro Occipital Technique (SOT) implies [6] a chiropractor and osteopath, found a similar relationship between the sacrum and occiput, as well as between the cervical and lumbar vertebrae [7]. SOT is a low-force chiropractic technique which is a system that uses the patient's body weight and breathing to allow the precise positioning of the blocks to align the spine and sacrum [8]. The orthopedic blocks, or wedges, serve as fulcrums that apply a slow gravitational load to the SIJ [9]. The SIJs and ligaments contain mechanoreceptors that signal for muscular reactions [10]. 
The weight-bearing part of the sacroiliac joint is a hyaline immovable articulation rich in proprioceptive fibers. It carries the weight of the body in all positions. Due to weight-bearing dysfunction of the sacroiliac joints, leg length should be a direct reflection of sagittal plane rotation of the ilia [11]

Pelvic Belts (PBs) improve health related quality of life which are potentially attributed to decreased SIJ related pain and improved postural steadiness during locomotion. Different from common lumbar orthoses, PBs are worn lower across the base of the sacrum and or just inferior to the ASIS [12]

\section{Patients and Methods}

Upon approval of Cairo University's supreme council of post graduate studies and research, the study extended from March 2018 to July 2018. This study was conducted at Mansoura University Hospital, El-Dakahlia, Egypt.

Thirty female patients with an age range from 25-35 years was randomly assigned into two groups, each group consists of 15 patient. Control Group (A) treated by Therapeutic ultrasound and study Group (B) treated by Sacro-occipital technique + Pelvic belt + Therapeutic ultrasound, referred from orthopedist with the diagnosis of Sacroiliac joint pain. All patients were given a full explanation of the protocol of the study and signed a consent form before participation in the study. The inclusion criteria were as follows: Female patient 25-35 years old, presence of sacroiliac weight bearing dysfunction (category two), positive Arm Fossa Test [8]. Positive leg length discrepancy and body mass index (25-30). The exclusion criteria were as follows: Any history of neurological disorders, infections, lumber disc prolapse, previous surgeries [13], receiving any medication for pain relieve at least 10 days before the beginning of treatment till the end of evaluation [13], any cognitive or language barriers [14], pregnancy and during menstrual period.

\section{Instrumentation:}

Blocks are a wooden wedge-shaped, measuring 8 X 4 X 4 inches (angled 45 degrees) Fig. (1) [13] Pelvic Inclinometer Fig. (2) [15], pelvic belt Fig. (3) $[16]$

\section{Assessment:}

1- Pelvic inclinometer: It's the most common measurement tool used by the clinicians to measure the pelvic tilt [17]. The validity of the pelvic inclinometer is 0.93 [15]. The inter rater reliability of the digital pelvic inclinometer for measuring pelvic tilt was designated as good on both sides (ICC $=$ 0.81-0.88) [18]. Patient is standing with bare feet on a level floor that were 6 inches apart, then the patient will instructed to maintain his eyes on the wall and cross the arms in front of the chest to minimize postural sway. The investigator placed his finger tips, stabilized in the finger braces over the anterior superior iliac spine, leveled the inclinometer in the frontal plane, and read the inclination from the liquid crystal display [13]

2- The Arm Fossa Test: The patient is supine; eyes open staring straight ahead, mouth closed and arm held in flexion, with palm medial and hand closed in a loose fist. The examiner gently grasps the patient's wrist with all fingers with the thumb wrapped around the wrist. The patient is then asked to resist the doctor's footward pull. The examiner then places four fingers in a line just inferior to the anterior superior iliac spine, which covers the upper fossa. The patient is asked to resist the footward pull again. The examiner's hand then moves down where his/her little finger stopped, and then moved an inch inferior to that, so that the hand is in place for the lower fossa. The patient is asked to resist again. Move clockwise, to the other side, and test the opposite upper fossa, then lower.

\section{Treatment:}

1-Placement of blocks: The patient lies in supine position with a straight spine on a pelvic board so that the pelvis is correctly supported. Blocks are placed between the pelvis and the board, one block is placed on iliac crest and the other is placed diagonally at 45 degrees facing the anterior superior iliac spine on the opposite side of the greater trochanter. The blocks adjusted until the height of the pelvis is equal on each side and the patient felt comfortable. All the blocks are removed after 5 minutes and then the arm fossa is repeated [13]. The blocking procedure of 5 minutes is performed day other day for 2 weeks (6 sessions). If the blocks are placed properly, inguinal ligament sensitivity will begin to subside within 30-60 seconds of block placement. Re-evaluate the bilateral pelvic tilting after 2 weeks from the first treatment session [19]

2- Pelvic belt: Patient instructed to wear the belt just below anterior superior iliac spine after each session to maintain adjustment [16] all the day except during bed rest. 


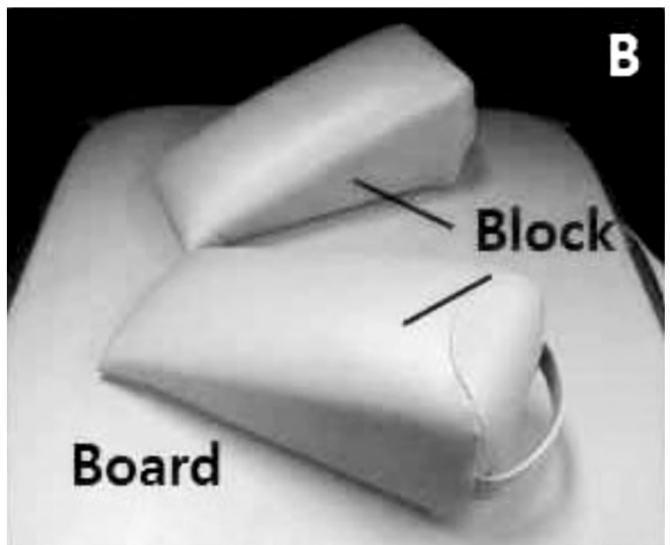

Fig. (1): Blocks.

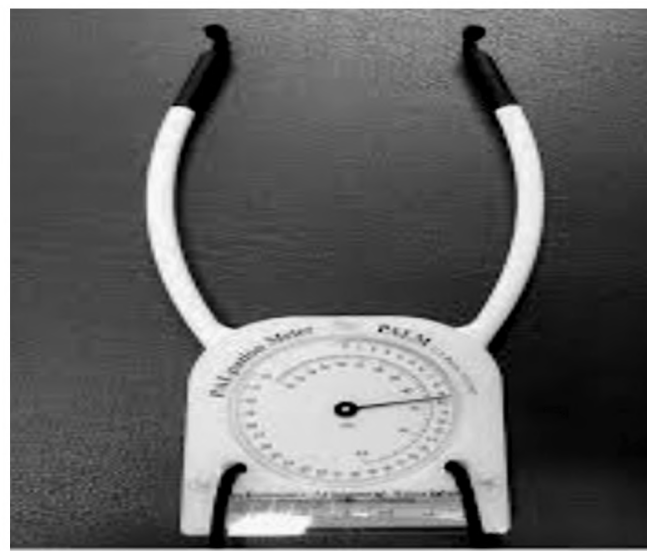

Fig. (2): Pelvic inclinometer.

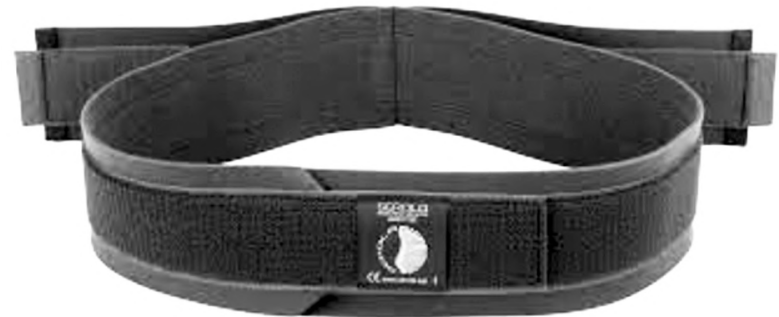

Fig. (3): Pelvic belt.

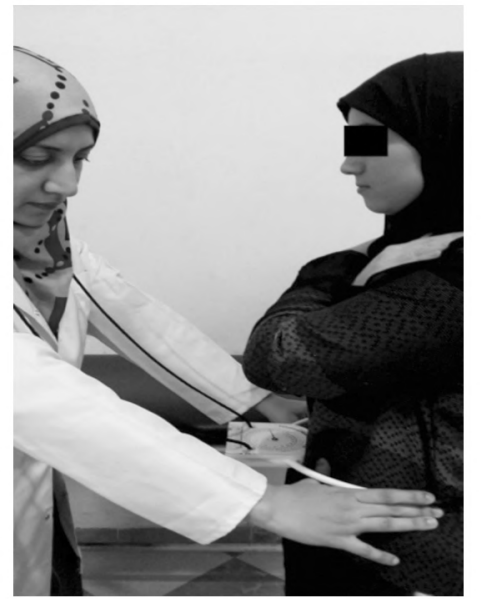

Fig. (4): Pelvic inclinometer procedure.

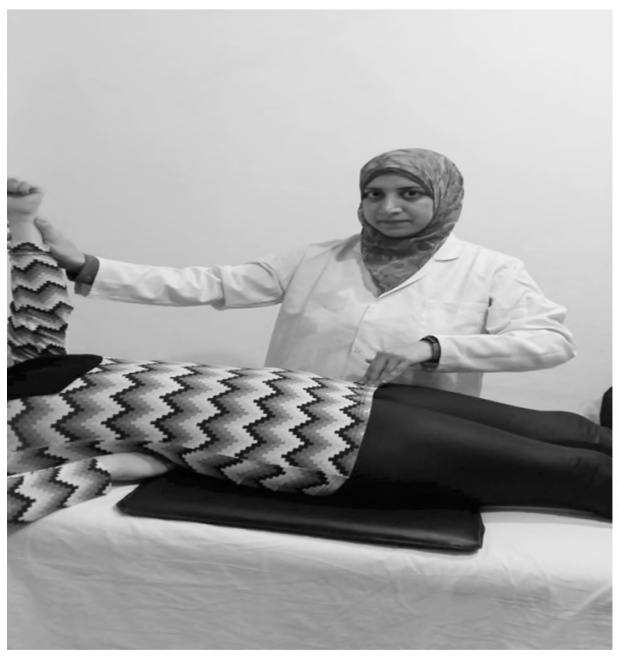

Fig. (5): Arm fossa test.

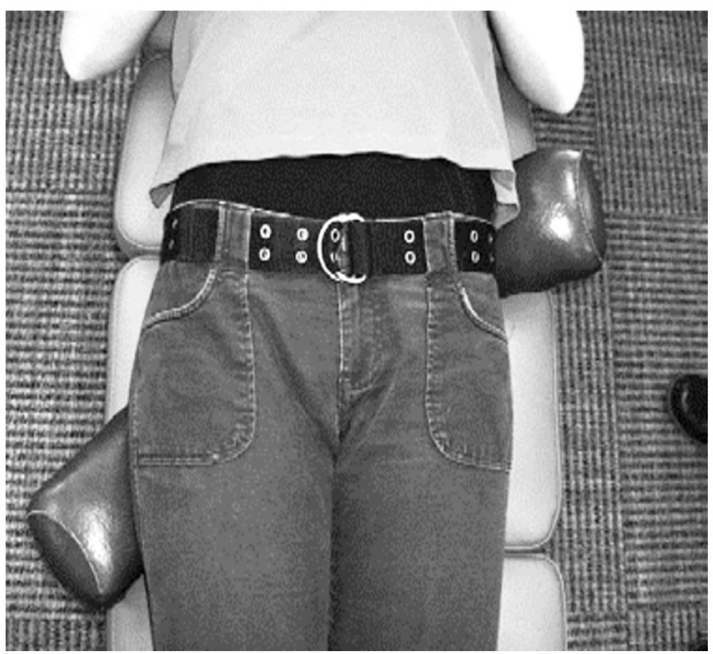

Fig. (6): Supine blocking procedure.

\section{Results}

Statistical analysis was done by using independent samples $t$-test for equality of means. The alpha level was set at 0.05 for the analysis.

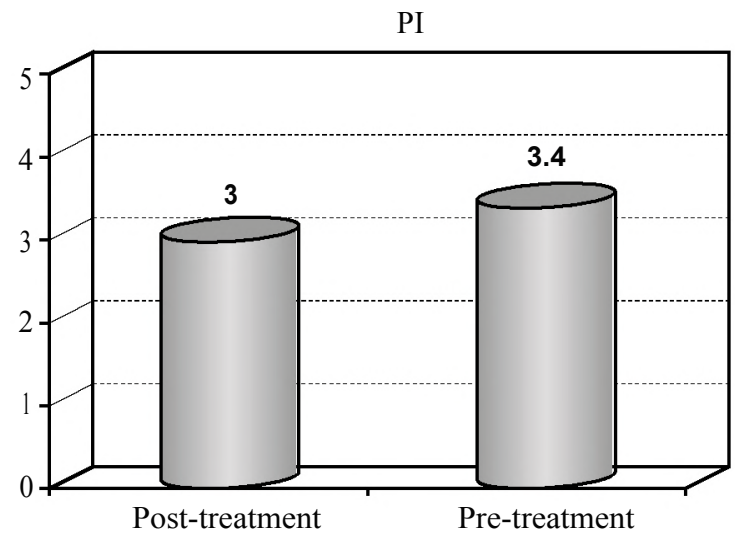

Fig. (7): The mean values of PI before and after treatment in group A. 
The mean and standard deviation values of the pelvic obliquity measurements in the two groups before and after the Sacro occipital technique category II blocking intervention are shown in (Tables 1,2) according to the analysis, the variable

PI

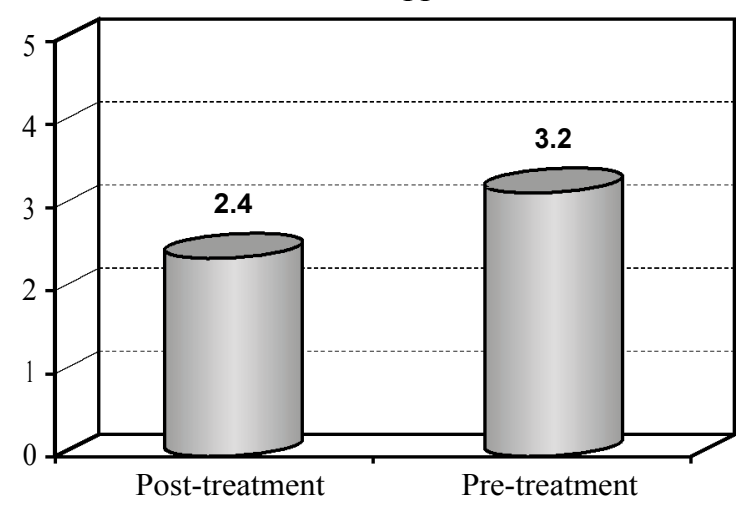

Fig. (8): The mean values of PI before and after treatment in group B. outcomes after the treatment in both control (A) and study (B) groups revealed that there is no significant difference in pelvic inclinometer in (control group A) $3.4( \pm 1.12)$ and a significant difference in (study group B) $2.4( \pm 0.632)$.

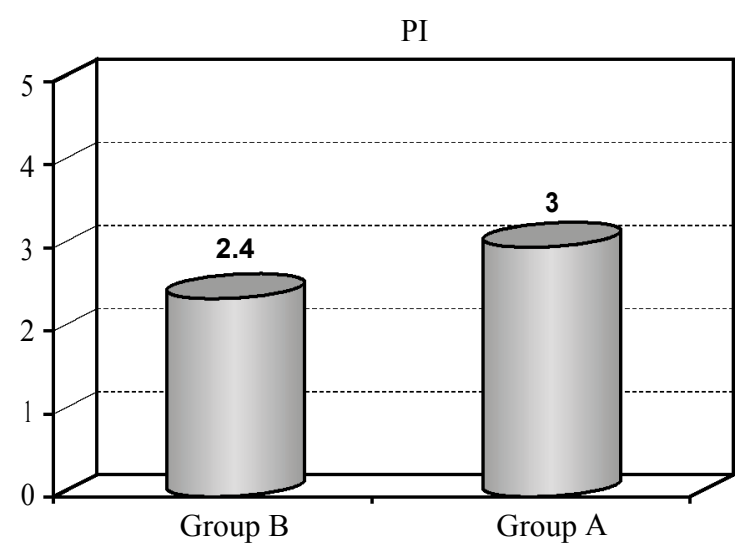

Fig. (9): The mean values of PI post-treatment for group A and group $\mathrm{B}$.

Table (1): The mean value of outcome of pelvic inclinometer before and after treatment in group A.

\begin{tabular}{|c|c|c|c|c|c|c|c|c|}
\hline \multirow{2}{*}{ Variable } & \multicolumn{3}{|c|}{ Pre-treatment } & \multicolumn{3}{|c|}{ Post-treatment } & \multirow{2}{*}{$\begin{array}{c}t- \\
\text { value }\end{array}$} & \multirow{2}{*}{$\begin{array}{c}p- \\
\text { value }\end{array}$} \\
\hline & Range (max-min) & Mean & S.D. & Range (max-min) & Mean & S.D. & & \\
\hline PI & $2-5$ & 3.4 & 1.12 & $2-4$ & 3 & 0.845 & -1.540 & 0.145 \\
\hline
\end{tabular}

Table (2): The mean value of outcome of pelvic inclinometer before and after treatment in group B.

\begin{tabular}{|c|c|c|c|c|c|c|c|c|}
\hline \multirow{2}{*}{ Variable } & \multicolumn{3}{|c|}{ Pre-treatment } & \multicolumn{3}{|c|}{ Post-treatment } & \multirow{2}{*}{$\begin{array}{c}t- \\
\text { value }\end{array}$} & \multirow{2}{*}{$\begin{array}{c}p- \\
\text { value }\end{array}$} \\
\hline & Range (max-min) & Mean & S.D. & Range (max-min) & Mean & S.D. & & \\
\hline PI & $2-5$ & 3.2 & 1.08 & $2-5$ & 2.4 & 0.632 & -4.582 & $0^{*}$ \\
\hline
\end{tabular}

*: Sig. $p<0.05$.

Table (3): Comparison of variable outcomes after the treatment of both groups revealed that there is A significant difference in pelvic inclinometer after blocking.

\begin{tabular}{|c|c|c|c|c|c|c|c|c|}
\hline \multirow{2}{*}{ Variable } & \multicolumn{3}{|c|}{ Pre-treatment group A } & \multicolumn{3}{|c|}{ Post-treatment group B } & \multirow{2}{*}{$\begin{array}{c}t- \\
\text { value }\end{array}$} & \multirow{2}{*}{$\begin{array}{c}p- \\
\text { value }\end{array}$} \\
\hline & Range (max-min) & Mean & S.D. & Range (max-min) & Mean & S.D. & & \\
\hline PI & $2-5$ & 3.4 & 1.12 & $2-5$ & 2.4 & 0.632 & 2.2013 & $0.0361 *$ \\
\hline
\end{tabular}

\section{Discussion}

Sacroiliac function is considered to be important in many manual therapy systems because of the complexity and location of the SIJ in the kinetic chain [4]

Normal lumbar function is, to a degree, dependent upon normal pelvic function. The sacroiliac joint creates a kinetic link between the spine and the lower extremities. The four spinal regions are interdependent on each other for full spinal normal function [20].

Sacro Occipital Technique (SOT) depends upon correct functioning of the SIJ. Normal functional balance of the pelvis depends on mechanics, neurology and physiology of the body i.e. normal structure produces normal function. The pelvis 
needs to be balanced and maintained in order to balance the rest of body [8].

SOT consider that the anterior and posterior aspects of the SI joint are completely different in both their anatomy and function. The posterior aspect has hyaline cartilage and is a weight-bearing joint that should not have much, if any, motion. On the other hand, the anterior aspect has a synovial bed, which allows for the joint nutation and whose motion purportedly aids in Cerebrospinal Fluid (CSF) mixing in a cranial ward direction [19].

SOT postulates that the scalene/first rib [21] area relates to category two due to visual and vestibular righting reflexes [22] an attempt of the body to maintain an upright posture when challenged by the assymetrical joint-loading of one SI joint in the category two patient [19]

The types of joint dysfunctions are classified into category I, II, and III depending on their condition [2]. Category II dysfunction is found in patients suffering from posterior SI joint hypermobility, which can lead to buttock pain, sciatic leg pain, groin pain, hip pain, abnormal urinary frequency, and transient numbness, prickling, or tingling [3].

Category two involves the importance of sacroiliac joint ability to resist stresses of forces directed into them by gravity and the force of walking, running and jumping. Category two adjusting deals with the correction of this decreased weight-bearing ability of the sacroiliac joint. Whenever the pelvic joints loose their integrity, the neuro-muscular system will innately compensate. Blocking is used to correct the pelvic dysfunction associated with the category two patients [23].

Category two involves sacroiliac joint mobility. Disorders in movement result from a sprain or separation of the innominate from the sacrum, with possible swelling. This occurs suddenly during some type of bending and twisting, or slipping and falling motion. The swelling creates proprioceptor system tension and may reflex to any musculoskeletal area of the body [8].

SOT is an indicator-based system that uses the patient's report of pain and tension at specific locations to guide treatment, since if the "indicators" worsen, the treatment would need to be modified. If they improve, the doctor knows they are going down the right path. The indicators help guide the doctor to realize the patient's progress independent of what a patient might say about his or her condition [19]. When the indicators and symptoms are not congruent, that indicates the need for more extensive diagnostic protocols [24]

Patients had to have proprietary SOT indicators of category II (sacroiliac weight-bearing dysfunction) exist by patient examination. The three indicators are the following: (1) Lateral sway of the entire spine to the left or right away from center as seen on plumb line analysis; (2) Unilateral palpatory pain and hypertonicity within the medial upper trapezius and scalene muscles; and (3) Palpatory muscle weakness of the posterior deltoid muscle during deep palpation of the origin of the sartorius or insertion of the rectus abdominus muscles on the anterior pelvis deltoid (known as the arm fossa test) [6]

In female; the joint tends to be more excavated, with a wider retroarticular and longer interosseous ligaments, all promoting a greater mobility. Pregnancy and hormonal in fluences of pregnancy and menstrual cycles participate in reversible ligament laxity [25]

The results of this study revealed that there is a significant difference between variables outcome after treatment by Sacro-occipital technique in (group B) compared to (group A). The pelvic obliquity is significantly decreased after the intervention than before. This is supported by many previous studies. Robert, 2003 comparing two groups of patients with SIJP by using true and false blocking, there is removing of the stress from the interosseous ligaments of the SIJ and correct the pelvic deviation in the group which using true blocking [20]. Moreover Hakata, 1990 comparing two groups of patients with SIJP by using true and false blocking, the results indicate a statistically significant difference in physical balance before and 2 days after the intervention [25]

Sacro occipital technique allow time for the nervous system to accommodate, the local connective tissue to remodel, and the lumbar vertebrae to experience gentle rotation or lifting pressures [7] Pelvic blocking requires no thrust; it does not bring the SIJ to tension into the physiological space and is very gentle [26].

Sacro occipital technique uses the patient's body weight and breathing to allow the precise positioning of the blocks to align the spine and sacrum [8]. The orthopedic blocks, or wedges, serve as fulcrums that apply a slow gravitational load to the sacro iliac joint [9]. The SIJs and ligaments contain mechanoreceptors that signal for muscular reactions [10]. The associated afferent pathways are intersegmental and in theory would allow a 
single mechanoreceptive stimulus to create a muscular response in kinetic areas distant from the site of stimulation [4]. Blocks allow ligaments to heal via gelation. Placing of the blocks induces an angular torque so the ligaments that have been stretched abnormally are allowed to tighten and shorten [27]

Pelvic belt may help stabilize the posterior sacro iliac ligaments when the patient is unable to maintain the adjustment [16].

\section{References}

1- KRISMER M. and VAN TULDER M.: "Low back pain (non-specific)", Best practice \& Research Clinical Rheumatology, Vol. 21, No. 12, 2007.

2- CHO IL-YOUNG: "Clinical Case study of Conservative Caring Method to Abnormal Knee Flexion in Standing Position", The Korea Contents Society, Vol. 8, No. 11, pp. 324-30, 2008.

3- SEMBRANO J.N. and POLLY D.W.: "How Often Is Low Back Pain Not Coming From The Back?" J. Spine, Vol. 34. No. 1. PP. E27-E32, 2009.

4- GIGGEY K. and TEPE R.: "Apilot study to determine the effects of a supine sacroiliac orthopedic blocking procedure on cervical spine extensor isometric strength" J. Chiropractice Med., Vol. 8, No. 2, pp. 56-61, 2009.

5- RATH J.D.: Mechanical low back pain in pregnancypreliminary findings in aconsecutive case series investigation, Philadelphia, Sept. 14, 1997.

6- DEJARNETTE M.B.: Sacro occipital Technique.privately published, Nebraska City, Nebraska, 210-33, 1984.

7- MONK R.: SOT Manual. Sacro Occipital Technique Organization-USA: Sparta, NC, 152-4, 2006.

8- SORSI Sacro occipital Research Society International: Sacro-Occipital Technique Manual, pp. 1-2, 8, 13-14, 19 20, 39-43, 45-46, 1992.

9- KNUTSON G.: The sacroiliac sprain: Neuromuscular reactions, diagnosis and treatment with pelvic blocking. Journal of the American Chiropractic Association, Aug., 41 (8): 32-9, 2004.

10- SLOSBERG M.: Effects of altered afferent articular input on sensation, proprioception ,muscle tone, and sympathetic reflex responses. J. Manipulative Physio. Ther. Vol. 11. No. 5: 400-8, 1988.

11- HOCHMAN J.I.: Sacro Occipital Technique in Context, SORSI, pp. 2-3, 5-8, 10,15, 1998.

12- HAMMER N., MOBIUS R. and HAMMER K.: Pelvic belt effects on health outcomes and functional parameters of patients with sacroiliac joint pain. PLOS one 10 (8), 2015.
13- KIM K.: Effect of sacro occipital technique category II Blocking on Attention and postural sway, 2013.

14- BLUM C.L.: R + C Factors and Sacro-Occipital Technique Orthopedic Blocking: Apilot study using pre and post VAS assessment. J. Can. Chiro. Assoc. Vol. 59. No. 2, 2015.

15- CROWELL R.D., CUMMINGS G.S. and WALKER L.J.: Intra tester and inter tester Reliability and validity of measures of innominate bone Inclination, Volume 20. N. 2 JOSPT, 1994.

16- MONK R.: SOT Manual. Sacro Occipital Technique Organization-USA, 2016.

17- HERRINGTON L.: Assessment of the degree of pelvic tilt within a normal asymptomatic population. Manual therapy, 16 (6): 646-8, 2011.

18- BEARDSLEY C., EGERTON T. and SKINNER B.: Test re-test reliability and inter-rater reliability of a digital pelvic inclinometer in young, healthy males and females. Peer. J., Dol. 10.7717/Peerj.188, 2016.

19- BLUM C.L.: Sacro-Occipital Technique "Category Two": A Remedy For Fixated Thinking. Dynamic Chiropractice. Vol. 24. No. 18, 2006.

20- ROBERT D.: " The Relationship between Pelvic Block Placement and Radiographic Pelvic Analysis". J. Chiropractic Medicine, Vol. 2, No. 3. pp.102-6, 2003.

21- BLUM C.L. and CURL D.D.: The relationship between sacro-occipital technique and sphenobasilar balance. Part One: The key continuities. Chiropractic Technique, Aug., 10 (3): 95-100, 1998.

22- MORNINGSTAR M., PETTIBON B., SCHLAPPI H. and SCHLAPPI M.: Ireland T. Reflex control of the spine and posture: A review of the literature from a chiropractic perspective. Chiro \& Osteop., 13: 13-6, 2005.

23- HOCHMAN J.I.: SOT: General Adjusting Strategy and Category 2, today's Chiropractic, July/August, part three: pp. 50-5, 1996.

24- BLUM C.L.: Incongruent sacro-occipital technique examination findings: Two unusual case histories. Proceedings of the ACC Conference IX. Journal of Chiropractic Education Spr., 16 (1): 67, 2002.

25- HAKATA S.: "Arthrokinematic Approach", Ishiyaku pub. Inc., Tokyo, Japan, 1990.

26- HOCHMAN J.I.: The Effect of Sacro Occipital Technique Category II Blocking On Spinal Ranges of Motion: A Case Series. J. Manipulative Physio. Ther. Vol., 28. pp. 719-23, 2005.

27- ZUSMAN G.S. and BUDDINGH C.C.: Biomechanical advantages of Dejarnette blocking. The Sacro Occipital Research Society International Winter conference Hawaii. Feb., 1-7, 1988.

28- NARIYA A. and DOBARIYA K.: Effectiveness of Isometric exercises in patient with sacroiliac joint dysfunction. Aust. J. Basic and App. L. Sci., 7 (7): 230-3, 2013. 


\section{فاعلية تقنية العجزية القزلية على علم ثبات مفصل العجزية الحمرية الحقفية فى السيدات}

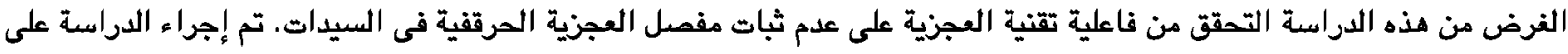

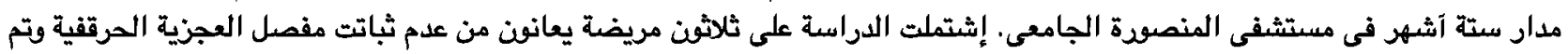

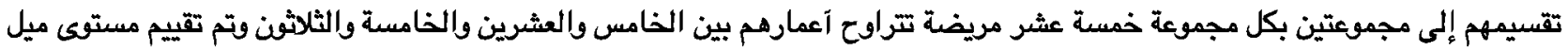
الحوض. آثبتت نتائج الدراسة فاعلية تقنية العجزية القزلية على تحسين مستوى ميل الحوض والذيى آدى بدوره إلى رفع الكفاءة الحركية وتقليل الإحساس بالآلم.

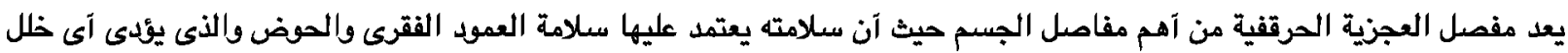

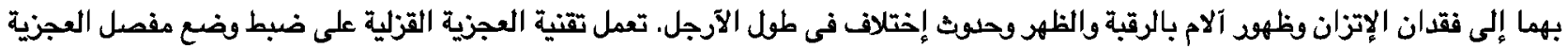

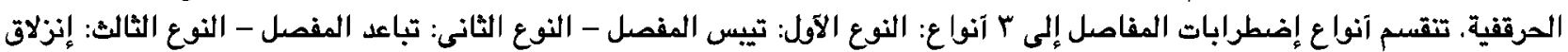
غضروفى بالمفصل.

تعتمد هذه الدراسة على معالجة النوع الثانى من الإضطرابات المفصلية والذى يؤدى إلى حدوث آلام فى المؤخره والآرجل وآيضا تقليل

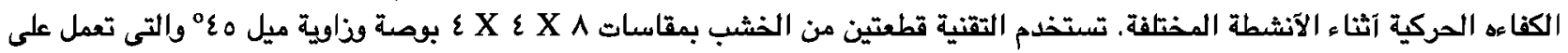

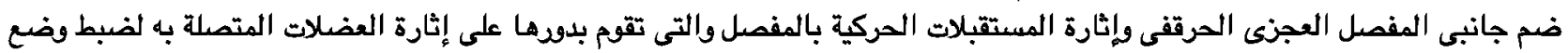
الجسم كما يعمل على سرعة إلتئام الآريطة المشدودة بعد وضعها في طولها الطبيعى.

آجريت الدراسة على السيدات فقط حيث آنهم أكثر قابلية للتعرض لميل الحضي الحض نتيجة الهرمونات الجنسية التى تساعد على مرونة الآريطة

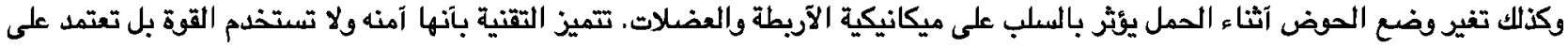
كتلة الجسم وحركة التنفس ويجب آن يشعر المريض بالراحة بمجرد بالئ وضع البلوك. مدة التقنية ه دقائق ويليها إرتداء حزام خاص بمفصل العجزية الحرتفية طوال اليوم ويخلع فقط آثاء النوم حتى إنتهاء الجلسات والتى ئى تستمر إسبوعين بمعدل 7 جلسات يوم بعد يوم. 